\title{
VERTICAL GASTRECTOMY AND GASTRIC BYPASS IN ROUX- EN-Y INDUCE POSTOPERATIVE GASTROESOPHAGEAL REFLUX DISEASE?
}

\author{
Gastrectomia vertical e bypass gástrico em Y-de-Roux induzem doença do refluxo gastroesofágico no pós-operatório? \\ Paulo Afonso Nunes NASSIF, Osvaldo MALAFAIA, Jurandir Marcondes RIBAS-FILHO, \\ Nicolau Gregori CZECZKO, Rodrigo Ferreira GARCIA, Bruno Luiz ARIEDE
}

From the Post-Graduate Program in Principles of Surgery, Evangelic Faculty of Paraná / University Evangelic Hospital of Curitiba / Medical Research Institute Curitiba, PR, Brazil.

HEADINGS - Gastric bypass. Anastomosis Roux-en-Y. Gastroesophageal reflux. Gastroenterostomy. Gastrectomy. Obesity. Bariatric Surgery.
ABSTRACT - Background: The association between obesity and gastroesophageal reflux disease has a high incidence and may be present in half of obese patients with surgical indication. Bariatric operations can also induce reflux alone - differently from BMI factors - and its mechanisms are dependent on the type of procedure performed. Objective: To perform a literature review comparing the two procedures currently most used for surgical treatment of obesity and analyze their relationship with the advent of pre-existing reflux disease or its appearance only in postoperative period. Method: The literature was reviewed in virtual database Medline/PubMed, SciELO, Lilacs, Embase and Cochrane crossing the following MeSH descriptors: gastric bypass AND / OR anastomosis, Roux-en-Y AND / OR gastroesophageal reflux AND / OR gastroenterostomy AND / OR gastrectomy AND / OR obesity AND / OR bariatric surgery AND / OR postoperative period. A total of 135 relevant references were considered but only 30 were used in this article. Also was added the experience of the authors of this article in handling these techniques on this field. Conclusion: The structural changes caused by surgical technique in vertical gastrectomy shows greater commitment of antireflux mechanisms predisposing the induction of GERD postoperatively compared to the surgical technique performed in the gastrointestinal Bypass Roux-en-Y.

\section{Correspondence:}

Paulo Afonso Nunes Nassif

paulonassif@terra.com.br

Financial source: none

Conflicts of interest: none

Received for publication: 04/11/2014

Accepted for publication: 08/05/2014

DESCRITORES - Derivação gástrica. Anastomose em-Y de Roux. Refluxo gastroesofágico. Gastroenterostomia. Gastrectomia. Obesidade. Cirurgia bariátrica.
RESUMO - Introdução: A associação entre obesidade e doença do refluxo gastroesofágico apresenta alta incidência e pode estar presente em metade dos obesos com indicação cirúrgica. Operações bariátricas podem também induzir refluxo por si só - de modo diferente do fator IMC -, e seus mecanismos são dependentes do tipo do procedimento realizado. Objetivo: Efetuar revisão bibliográfica comparando os dois procedimentos atualmente mais utilizados para tratamento cirúrgico da obesidade e analisar a relação deles com o advento de doença do refluxo gastroesofágico pré-existente ou de surgimento somente no pós-operatório. Método: Foi realizada revisão bibliográfica nas bases virtuais Medline/Pubmed, Scielo, Lilacs, Embase e Cochrane cruzando os seguintes descritores MeSH: gastric bypass AND/ OR anastomosis, Roux-en-Y AND/OR gastroesophageal reflux AND/OR gastroenterostomy AND/OR gastrectomy AND/OR obesity AND/OR bariatric surgery AND/OR postoperative period. Foram consideradas pertinentes 135 referências e utilizadas 30 neste artigo. Também foi adicionada a experiência dos autores deste artigo no manuseio dessas técnicas com esse mister. Conclusão: As alterações estruturais causadas pela técnica operatória na gastrectomia vertical apresenta maior comprometimento dos mecanismos anti-refluxo predispondo a indução da DRGE no pós-operatório quando comparado à técnica operatória realizada no Bypass gastrointestinal em Y-de-Roux.

\section{INTRODUCTION}

$T$ he association between obesity and gastroesophageal reflux disease (GERD) presents high incidence and may be present in half of obese patients with surgical indication ${ }^{25,36}$. The incidence of GERD in the non-obese population is $15-20 \%$ and Barrett's esophagus 1-2\%. Already, in obese ranges from $22-70 \%$ and $7-30 \%{ }^{17}$, respectively. Thus, obesity is a risk factor in the pathogenesis of reflux. Bariatric operations can also induce reflux alone - differently from BMI factors - and its mechanisms are dependent on the type of procedure performed ${ }^{10,34,36,41}$.

Structural changes caused by bariatric interventions affect the motor functions of the organs involved differently from one another.

The sleeve gastrectomy or gastric sleeve and gastric bypass Roux-en-Y are comparable in weight loss, but appear to differ in their effects on comorbidities ${ }^{48}$. Information from large databases suggest that these procedures improve the symptoms of GERD with superiority for gastric bypass ${ }^{34}$. Smaller prospective studies indicate that the sleeve gastrectomy may predispose to GERD "de novo"13.

Roux-en-Y gastric bypass has become the gold standard operation, widely used by its results in weight loss, control of comorbidities, including the improvement of gastroesophageal reflux 8 . The sleeve gastrectomy - originally presented as the first step to the duodenal switch - for their good results established popularity as one definitive procedure $^{2,18}$; however, the effect of it is unknown in GERD and some studies ${ }^{7,14,15}$ 
have suggested that anatomical changes introduced may exacerbate or induce symptoms in previously asymptomatic patients. Tutuian ${ }^{44}$ evaluating the effects of bariatric surgery on GERD reports its emergence in $10 \%$ of patients undergoing gastrectomy who were asymptomatic preoperatively as reflux; also notes that the gastric bypass Roux-en-Y improves preexisting GERD symptoms in most patients.

The technique of vertical sleeve gastrectomy is not yet fully standardized. There tend to be held more frequently to be effective in weight loss, provide good postoperative results and low morbidity ${ }^{1}$. However GERD as a result of this operation was still unclear.

Thus, the objective of this review is to perform a literature search comparing the two procedures currently most used for surgical treatment of obesity and analyze their relationship with the advent of pre-existing reflux disease or its appearance only in postoperative period.

METHOD

Literature review was performed in virtual Medline / PubMed, SciELO, Lilacs, Embase and Cochrane crossing the following MeSH descriptors: gastric bypass AND / OR anastomosis, Roux-en-Y AND / OR gastroesophageal reflux AND / OR gastroenterostomy AND / OR AND gastrectomy / obesity OR AND / OR bariatric surgery AND / OR postoperative period. A total of 135 relevant references were considered and 30 used in this article.

\section{Surgical technique of gastrectomy / gastric sleeve}

Alternative proposals for gastrectomy in a greater or lesser extent maintain antropyloric area; vertically remove most of the gastric body from the imaginary line that divides the gastric body and antrum and completely eliminate the fundus ${ }^{29}$. Considering the internal dynamics and the vectors of physiological strength of gastric cavity with these resections - part of the body, total fundus and maintaining the antrum - greater accumulation of gastric juice in antropyloric lumen occurs. As the fund no longer exists - the main element of contention in the anatomofunctional antireflux mechanism liquid reflux to the distal esophagus becomes potential reality. Withdrawal external pressure exercised by the movement of the esophageal hiatus during breathing ("external esophageal sphincter"), the pressure of the lower esophageal sphincter becomes the only obstacle to the gastric fluid to not enter freely into the esophagus. In greater amounts in the distal stomach, gastric intraluminal content would further pressure the esophagogastric junction and force the sphincter, overcoming it ${ }^{38}$ (Figure 1 ).
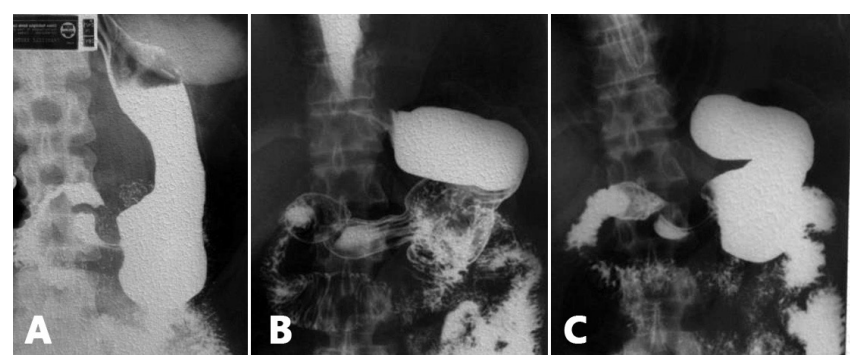

FIGURE 1 - Case of sleeve gastrectomy at four years postoperatively in the usual way to run it: A) there is complete loss of the esophagogastric angle transforming junction area like an inverted funnel, directing the gastric contents into the esophagus which appears with open cardia; B) its noticeable that the stomach attempts, over time, to redo its lost anatomy; C) anatomical evidence of dilatation of the bodyantral region
But the authors of this paper believe that rather than leaving the antrum almost intact - as is usually done - better is to do a tubulization on the lesser curvature calibrated by a probe, modeling it over a Fouchet $32 \mathrm{~F}$, from the esophagogastric junction to pylorus - transposing it - to obtain smaller cubic volume in the gastric lumen (Figure 2).
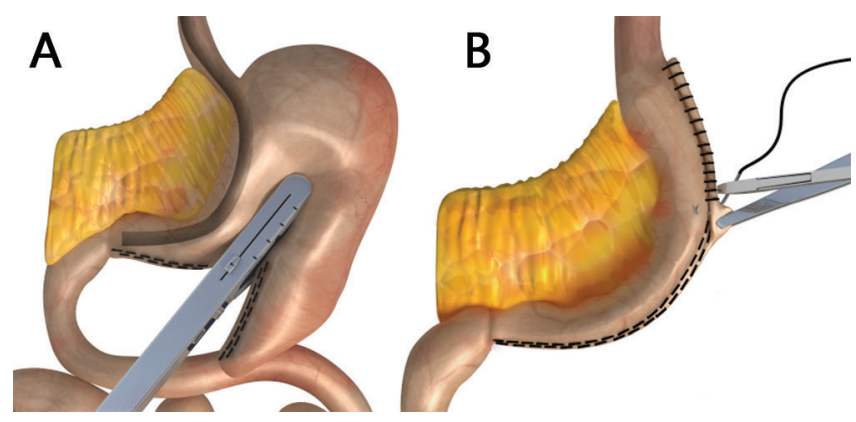

FIGURE 2 - Modification of the vertical gastrectomy proposed by the authors ${ }^{31}$ : A) section and stapling of gastric antrum and body from the pylorus toward the esophagogastric angle; B) end view of the staple line showing the tubular form of the stomach, modeled from cardia to the pylorus by $32 \mathrm{~F}$ Fouchet probe, placed in the sight on $A$

In lower amount, gastric intraluminal fluid does not force the lower esophageal sphincter and, thus, can give him the opportunity to play normally (or near) its physiological functions, despite the anatomical changes caused by the operation. Even having reflux, it would be in a lower amount providing less aggression to distal mucosa. It was learned with gastric tubing in transmediastinal esophagectomies - in which was based this modified technique - that with lower tubulized cavity lower is the potential for reflux, and gastric emptying is done more rapidly to the duodenum ${ }^{38}$ (Figure 3 ).

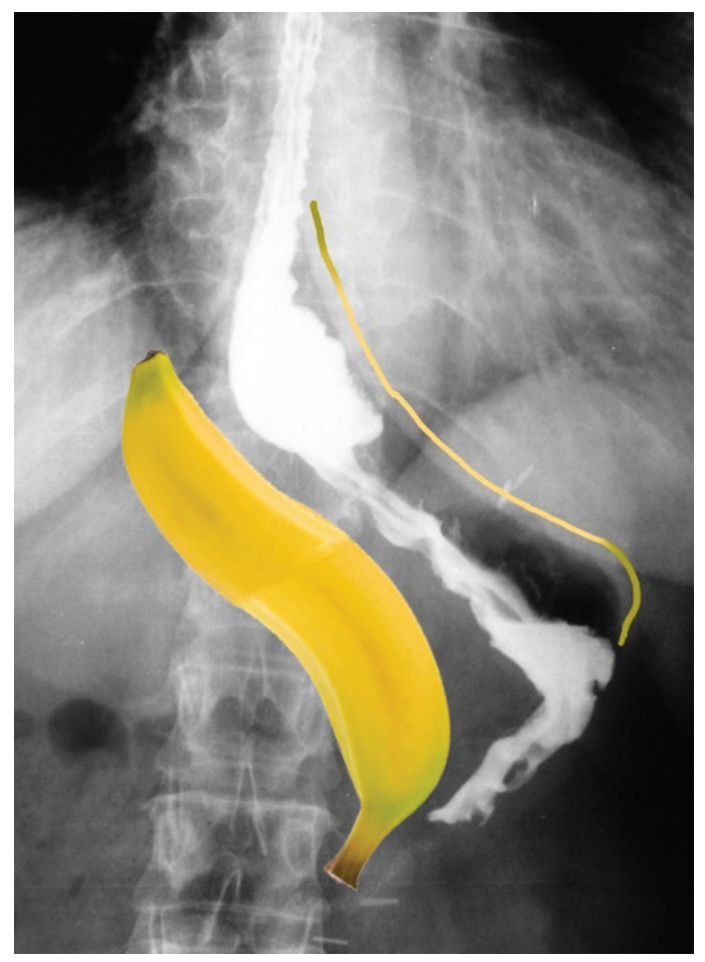

FIGURE 3 - Radiography of a patient undergoing vertical gastrectomy with the tubing proposed technical modification; intragastric cavity gets smaller, configuring itself as a thin "banana" 
Although Nassif et al. ${ }^{31}$ have proposed this modified technique in previous publication, they didn't say that it will totally prevent postoperative GERD. The authors are conducting studies to quantify and qualify the refluxate that can harm the distal esophagus and check which pathological consequences it would further promote.

Surgical technique of Roux-en-Y gastric bypass

Begins the operative procedure identifying the duodenojejunal angle. From there, measuring 10 by 10 $\mathrm{cm}$ to $100 \mathrm{~cm}$, determine the point of entry of future biliopancreatic jejunal loop, and divide it at this point. The jejunum above this point will make up part of the feed loop that is complemented by the extension of the gastric pouch, staying with approximate length of 110 $\mathrm{cm}$. Next step is jejunojejunoanastomosis. To perform the gastric pouch, which will replace the stomach to its original form, is necessary to access the lesser omentum creating a retrogastric window. The procedure is then clipping the first to delimit the length? the new stomach. To determine the width of this gastric pouch one second stapling towards the esophagogastric angle is done modeled by a Fouchet $32 \mathrm{~F}$ probe. Finally, gastrojejunal anastomosis is done, completing the gastric pouch. All lines are reinforced by an oversuture (Figure 4).

The small gastric pouch produces too little acid secretion and the long stretch of food loop $(110 \mathrm{~cm})$ - acquired in making the Roux-en-Y - functions as a "functional sphincter"; peristaltic movement along this segment prevents the entrance of biliopancreatic secretions coming through the biliopancreatic loop, anastomosed to the jejunum in the previously marked site, to reflow and eventually to reach the gastric pouch and distal esophagus, ie $110 \mathrm{~cm}$ above. Thus, what can flow back into the esophagus is only part of the local mucous liquid, harmless to the mucosa, and food debris still passing by that produce no reflux esophagitis (acid or mixed) $)^{11}$

\section{RESULTS}

Vertical gastrectomy / gastric sleeve and GERD

Few published studies address the changes in gastrointestinal motility and reflux after vertical gastrectomy. Some ${ }^{3,27}$ have shown that gastric emptying was accelerated with the procedure. Another ${ }^{27}$ suggested that surgical section of the ligaments around the abdominal esophagus, phrenoesophageal membrane and destruction of the esophagogastric junction could explain the worsening or onset of symptoms of GERD. The sleeve gastrectomy can induce weight loss by reducing food intake; but, by presenting accelerated gastric emptying, may reduce the feedback signals of satiety precipitating hunger episodes and, thus, decreasing the interval between consecutive meals ${ }^{3}$. Interestingly, several authors found no difference in emptying with this procedure between lean and obese subjects.

After resection of the gastric fundus - a leading producer of local ghrelin - occurs abrupt drop in its level, leading to hunger decrease. In early satiety mechanism are involved hormones, decreased gastric motility and gastric tube high pressure.

In sleeve gastrectomy, gastric emptying can change by several mechanisms: 1 ) the removal of the gastric fundus with its receptive and propulsion functions; 2) restriction, low distensibility of the tube and high intraluminal pressure; 3 ) removal of the gastric pacemaker body area of the stomach ${ }^{32}$; 4) difficulties on antral pump action if part of the antrum is resected.

Bernstine et al. demonstrated that gastric emptying is not altered after gastrectomy when the antrum is preserved; also, said that the antral preservation prevents the dumping syndrome and gastroesophageal reflux. Weiner et al. ${ }^{47}$ also recommended to protect the antrum due to its importance in the pumping mechanism for gastric emptying. Melissas et al. ${ }^{27}$, in turn, found scintigraphic evidence of faster gastric emptying. Michalski et al. ${ }^{29}$ also in scintigraphic study with resection of the antrum, showed increased gastric emptying postoperatively when compared with group of patients with its preservation. Is evident from these results that the topic is controversial and deserves further research in this direction.

Using traditional manometry, Braghetto et al. ${ }^{6}$ reported that sphincter pressure decreases after vertical gastrectomy due to the section of the muscle fibers (Figure 5A) in the esophagogastric junction after stomach stapling near the esophagogastric angle (Figure 5B). Himpens et al. ${ }^{37}$ hypothesized that lack of compliance by removing the gastric fundus and the absence of the esophagogastric angle are responsible for the increase of GERD one year after sleeve gastrectomy.
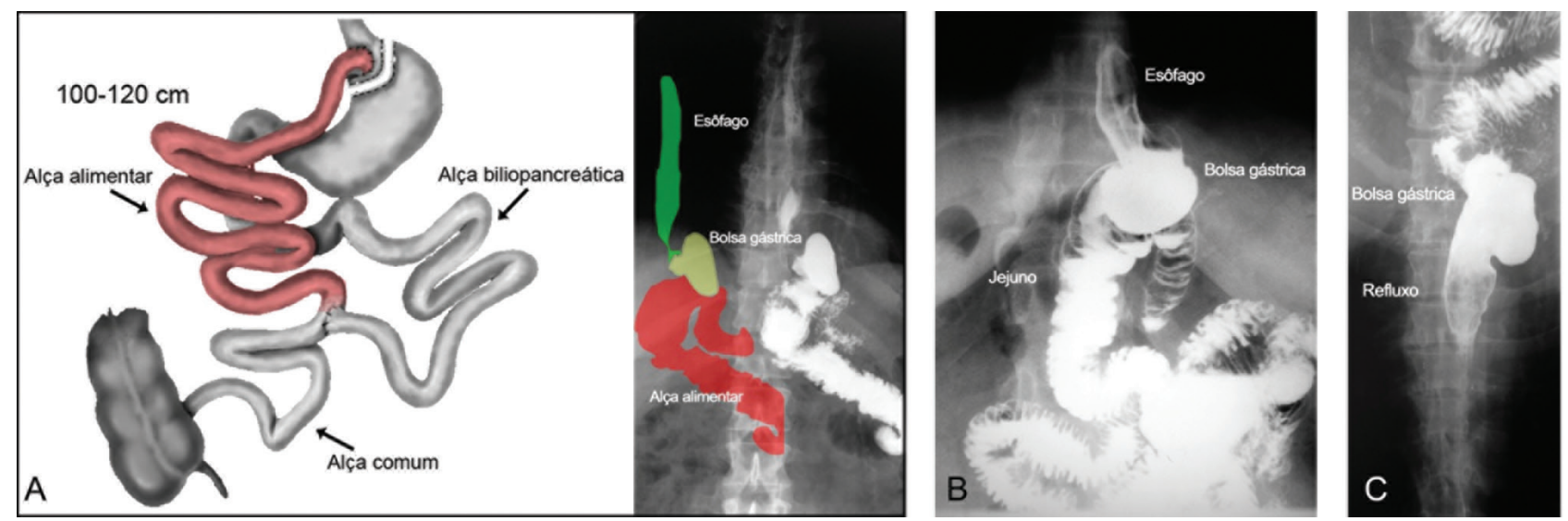

FIGURE 4 - Roux-en-Y gastric bypass: A) figure showing the feed loop of $100 \mathrm{~cm}$ or more that plays the role of "functional sphincter"; B) X-ray image with terminolateral anastomosis between the gastric pouch (terminal) and jejunum (lateral); C) radiograph showing "reflux / regurgitation" of gastric contents into the esophagus during radiographic maneuver inducing reflux (Bruno: colocar em inglês as palavras) 

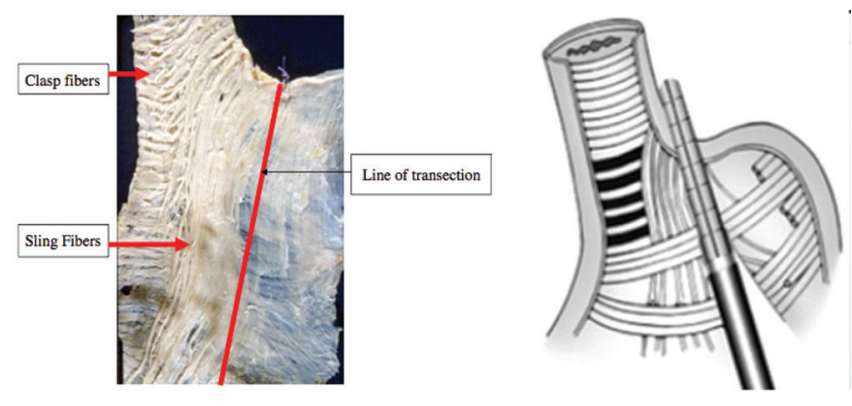

FIGURE 5 - Arrangement of fibers in the muscle layer of the anatomical esophagogastric complex: A) cadaveric dissection and marked staple line; B) schematic drawing of the clipping

HoweverPetersenetal. ${ }^{35}$ reported thatthesleevegastrectomy significantly increased sphincter pressure, independent of weight loss, and it may protect obese patients from reflux. Del Genio et al. ${ }^{13}$ in turn, presented first objective data on how this operation can be performed correctly and can not affect the lower esophageal sphincter. In the modification proposed by the authors of this paper, there can be no great impact on the sphincter pressure probably due to the integrity of muscle fibers in the esophagogastric junction that is best preserved by driving up the last stapling to the left and keeping it at least $1 \mathrm{~cm}$ away from the esophagogastric junction. The progression of the alimentar bolus has been tested directly by impedanciometry studying all flows and movements of the esophagus ${ }^{13}$; as a result, was demonstrated decreased on oesophageal transit after the operation due to increase ineffective peristaltic waves and changes in esophageal dynamics during swallowing ${ }^{13}$.

Person with intact stomach is able to complete a meal without regurgitation, vomiting or reflux, whereas after vertical gastrectomy tube causes a reduction in gastric compliance. Once the stomach is full, the intraluminal pressure increases according to the law of Laplace, food "bounces back" from the stomach into the esophagus. This phenomenon, due to intraluminal stasis - not GERD of "new" - produces esophageal acidification misinterpreted by monitoring by default as gastroesophageal reflux disease $\mathrm{pH}$. The sleeve gastrectomy has been implicated in the progression and/or "new" appearance of GERD in patients previously without reflux. Howard et al. ${ }^{23}$ $82 \%$ reported worsening of symptoms of reflux with its use. Tai et al. ${ }^{43}$ also observed a significant increase in the prevalence of GERD symptoms (12.1\% vs $47 \%)$ and erosive esophagitis ( $16.7 \%$ vs $66.7 \%$ ) after surgery in 66 patients with one year follow-up. However, Daes et al. ${ }^{12}$ reported that when it is found during surgery hiatal hernia should be reduced and perform the closure of the esophageal hiatus; with this done, the incidence of GERD decreased from $49.2 \%$ to $1.5 \%$ in $6-12$ months postoperatively (Nassif verify because I feel something wrong). "New" GERD symptoms developed in $22.9 \%$ of patients undergoing vertical gastrectomy alone compared with $0 \%$ of patients undergoing it associated to hiatal hernia repair. Finally, a recent review of the literature on the effect of sleeve gastrectomy in GERD noted that a total of 11 studies that had data for both pre- and postoperative observation, four reported an increase in GERD after operation and seven found prevalence reduction after it. The International Consensus on Vertical Gastrectomy held at the Biltmore Hotel, Coral Gables, Florida on 25 and 26 March 2011 including 24 centers with 12779 patients showed rate of 12.11 $+-8.97 \%$ of reflux postoperatively ${ }^{39}$.

\section{Roux-en-Y gastric bypass and GERD}

Gastroesophageal reflux tendency, being elevated in obese, can lead to oesophageal dysmotility ${ }^{28}$. Valezi et al. ${ }^{45}$ evaluating the manometry before and after gastrointestinal bypass established association between it and certain esophageal motor disorders - increased amplitude of contractions and decreased intake rate - but no effect on peristalsis and no difference in postoperative feeding. Concluded that the preoperative manometry changes can not be contraindication to the surgical procedure.

Gastric bypass has contributed in improving symptoms of GERD and esophageal acid exposure in most studies, due to the small size of the gastric pouch, the diversion of bile and almost all gastric acidity obtained by Roux-en-Y reconstruction ${ }^{26}$. It happens due to low pressure in the small gastric pouch, reduced exposure to acid and bile reflux and, as a whole, resulting in marked improvement of GERD. For these and many other reasons, it has been the procedure of choice for patients with GERD. Nelson et al. ${ }^{33}$ also observed an improvement of $94 \%$ in typical reflux symptoms after gastric bypass in nine-month study, with only $4 \%$ of worsening symptoms. Prachand et al. ${ }^{37}$ in turn, compared the resolution of comorbidities among patients undergoing Roux-en-Y gastric bypass or duodenal switch; latter procedure offered better weight loss, better control of diabetes mellitus, hypertension and hyperlipidemia, while the bypass was more effective in resolving GERD.

Studies 5,46 have shown improvement in GERD in patients undergoing fundoplication conversion to gastrointestinal bypass and reveal that the development GERD "de novo" after bypass, is quite unusual. Frezza et al. ${ }^{16}$ reported that up to $22 \%$ of patients who underwent bypass continued to report symptoms of GERD postoperatively. The main indications for conversion vertical gastrectomy into gastrointestinal bypass is unsatisfactory weight loss with no improvement in comorbidities and clinically intractable gastroesophageal reflux.

Treatment and prevention of GERD after sleeve gastrectomy and Roux-en-Y gastric bypass

The initial treatment of patients with symptomatic GERD after sleeve gastrectomy is with proton pump inhibitors, reserving surgery for patients with persistent GERD symptoms and evidence that undermines the quality of life. The technical choice falls over conversion to Roux-en-Y gastric bypass.

Several authors $39,40,42$ evaluated the effect of sleeve gastrectomy with or without correction of hiatal hernia in gastroesophageal reflux disease in obese patients. Whenever sliding hernia was found intraoperatively they performed dissection to release and identify the esophagus and the diaphragmatic hiatus. The part of the stomach above the esophagogastric junction was released and replaced into the abdomen and subsequently the hiatal ring was closed. After this procedure, was done devascularization of the greater curvature to perform the gastrectomy. Current understanding is that the role of hiatoplasty is of an "external esophageal sphincter", represented by hiatal opening and closing movement during breathing. A sphincter external compressive mechanical action over the esophagus during inspiration movements is known to occur, leading to higher and lower intra-abdominal pressure changes when monitoring these movements. In inspiration occurs tendency to reflux of gastric contents into the esophagus due to increase in intra-abdominal pressure, which at the same time is neutralized by movements of hiatal constriction, canceling it and therefore avoiding gastroesophageal reflux (Figure 6). 


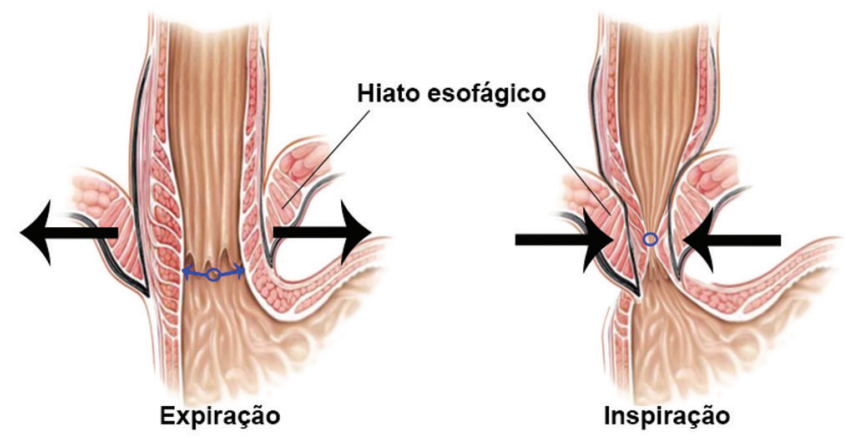

FIGURE 6 - Figure showing the hiatal ring (arrows) and its role in the dynamics of the sphincter complex, acting as "external sphincter" on the esophagus (esophageal clamping) during respiratory movements

Braghetto et al. ${ }^{5}$ indicated to obese patients with BMI> 30 fundoplication associated with vagotomy and distal Rouxen-Y gastrectomy, and suggested that in Barrett's esophagus gastric bypass 22,24 controls symptoms of esophagitis, promote local healing and permits regression of intestinal metaplasia. 4,11,19,20

Regarding the revisional operation few studies have addressed to the gastric bypass in patients with reflux clinically intractable ${ }^{30}$. The indications should be based on anatomical changes that may predispose to reflux. The most common are: 1 ) the presence of gastric fundus; 2 ) small extension of alimentary loop; and 3) failure of loss or reacquisition of weight. For the condition of remaining fundic area what should be done is to return to surgical resection. In case of insufficient length of the feed loop, re-operation will extend it to $100-120 \mathrm{~cm}$. To unsuccessful weight loss or re-fattening, it must be clarified if it occurred due surgical technique mistakes or just due to feed errors, which should be treated with changes in lifestyle habits and nutritional orientation.

\section{CONCLUSION}

The structural changes caused by surgical technique in vertical gastrectomy shows greater commitment of antireflux mechanisms predisposing the induction of GERD postoperatively compared to the surgical technique performed in the gastrointestinal Bypass Roux-en-Y.

\section{ACKNOWLEDGEMENTS}

The $A B C D$ thanks the permission given by the editors of the Book of Gastrão 2014 to adapt this review from a chapter written by the same authors and published on it with the same focus.

\section{REFERENCES}

1. Andriani AC, Neves TT. A gastroplastia em manga (Sleeve gastrectomy) e o Diabetes Mellitus. ABCD Arq Bras Cir Dig, 2008 21 (3): $133-5$

2. Anthone GJ. The duodenal switch operation for morbid obesity Surg Clin North Am. 2005;85(4):819-833, viii

3. Braghetto I, Davanzo C, Korn O, et al. Scintigraphic Evaluation of gastric emp-tying in obese patients submitted to sleeve gastrectomy compared to normal subjects. Obes Surg 2009; 19: 1515-21

4. Braghetto I, Csendes A, Korn O, et al. Laparoscopic resectional gastric bypass in patients with morbid obesity: experience on 112 consecutive patients. J Gastrointest Surg. 2011;15:71-80
5. Braghetto I, Korn O, Csendes A, Gutiérrez L, Valladares H, Chacon M. Laparoscopic treatment of obese patients with gastroesophageal reflux disease and Barrett's esophagus: a prospective study. ObesSurg.2012;22(5):764-772

6. Braghetto I, Lanzarini E, Korn O, et al. Manometric changes of the lower esophageal sphincter after sleeve gastrectomy in obese patients. Obes Surg. 2010;20(3):357-62. Epub 2009 Dec 15. PMID: 20013071.

7. Buchwald $H$, Avidor $Y$, Braunwald $E$, et al. Bariatric surgery: a systematic review and meta-analysis. JAMA. 2004;292(14):17241737.

8. Buchwald H, Buchwald JN. Evolution of operative procedures for the management of morbid obesity 1950-2000. Obes Surg. 2002;12(5):705-717.

9. Chiu S, Birch DW, Shi X, Sharma AM, Karmali S. Effect of sleeve gastrectomy on gastroesophageal reflux disease: a systematic review. Surg Obes Relat Dis 2011;7:510-5.

10. Csendes A, Braghetto I, Burdiles P, et al. Late results of the surgical treatment of 125 patients with short-segment Barrett's esophagus. Arch Surg. 2009;144:921-7

11. Csendes A, Braghetto I, Burdiles P, Korn O. Roux-en-Y long limb diversion as the first option for patients who have Barrett's esophagus. Chest Surg Clin N Am. 2002 Feb;12(1):157-84.

12. Daes J, Jimenez ME, Said N, Daza JC, Dennis R. Laparoscopic sleeve gastrectomy: symptoms of gastroesophageal reflux can be reduced by changes in surgical technique. Obes Surg 2012;22: 1874-9.

13. Del Genio G, Tolone S, Limongelli P, Brusciano L, D'Alessandro A, Docimo G, Rossetti G, Silecchia G, Iannelli A, del Genio A, del Genio F, Docimo L. Sleeve gastrectomy and development of "de novo" gastroesophageal reflux. Obes Surg. 2014 Jan;24(1):71-7. doi: 10.1007/s11695-013-1046-4.

14. DeMariaEJ, Schauer $P$, Patterson $E$, et al. The optimal surgical management of the super-obese patient: the debate. Presented at the annual meeting of the Society of American Gastrointestinal and Endoscopic Surgeons, Hollywood, Florida, USA, April 13-16, 2005. Surg Innov. 2005;12(2):107-121

15. Elder KA, Wolfe BM. Bariatric surgery: a review of procedures and outcomes. Gastroenterology. 2007;132(6):2253-2271

16. FrezzaEE,Ikramuddin $S$, Gourash W, etal.Symptomaticimprovement in gastroesophageal reflux disease (GERD) following laparoscopic Roux-en-Y gastric bypass. Surg Endosc. 2002;16(7):1027-1031.

17. Friedenberg FK, Xanthopoulos M, Foster GD, et al. The association between gastroesophageal reflux disease and obesity. Am J Gastroenterol. 2008;103:2111-22

18. Gagner M, Deitel M, Erickson AL, Crosby RD. Survey on laparoscopic sleeve gastrectomy (LSG) at the Fourth International Consensus Summit on Sleeve Gastrectomy. Obes Surg. 2013 Dec;23(12):2013-

19. Gómez Escudero O, Herrera Hernández MF, Valdovinos Díaz MA Obesity and gastroesophageal reflux disease. Rev Invest Clin. 2002;54:320-7

20. Hampel H, Abraham NS, El-Serag HB. Meta-analysis: obesity and the risk for gastroesophageal reflux disease and its complications. Ann Intern Med. 2005:143:199-211

21. Himpens J, Dapri G, Cadière GB. A prospective randomized study between laparoscopic gastric banding and laparoscopic isolated sleeve gastrectomy: results after 1 and 3 years. Obes Surg. 2006;16:1450-6.

22. Houghton SG, Romero Y, Sarr MG. Effect of Roux-en-Y gastric bypass in obese patients with Barrett's esophagus: attempts to eliminate duodenogastric reflux. Surg Obes Relat Dis. 2008;4:1- 4

23. Howard DD, Caban AM, Cendan JC, Ben-David K. Gastroesophageal reflux after sleeve gastrectomy in morbidly obese patients. Surg Obes Relat Dis 2011;7:709-13.

24. Kellog TA, Andrade R, Maddaus $M$, et al. Anatomic findings and outcomes after antireflux procedures in morbidly obese patients undergoing laparoscopic conversion to Roux-en- $Y$ gastric bypass. Surg Obes Relat Dis. 2007;33:52-7

25. Klaus A, Gruber I, Wetscher G, et al. Prevalent esophageal body motility disorders underlie aggravation of GERD symptoms in morbidly obese patients following adjustable gastric banding. Arch Surg 2006;141:247-51

26. Madalosso CA, Gurski RR, Callegari-Jacques SM, Navarini D, Thiesen $\mathrm{V}$, Fornari $\mathrm{F}$. The impact of gastric bypass on gastroesophageal reflux disease in patients with morbid obesity: a prospective study based on the Montreal Consensus. Ann Surg. 2010 Feb;251(2):244-8.

27. Melissas J, Koukouraki S, Askoxylakis J, et al. Sleeve gastrectomy - a restrictive procedure? Obes Surg 2007; 17: 57-62 
28. Merrouche M, Sabate J, Jouet P, et al. Gastro-esophageal reflux and esophageal motility disorders in morbidly obese before and after bariatric surgery. Obes Surg. 2007;17:894- 900

29. Michalsky D, Dvorak P, Belacek J, Kasalicky M. Radical resection of the pyloric antrum and its effect on gastric emptying after sleeve gastrectomy. Obes Surg. 2013 Apr;23(4):567-73

30. Morales MP, Wheeler AA, Ramaswamy A, Scott JS, de la Torre RA. Laparoscopic revisional surgery after Roux-en-Y gastric bypass and sleeve gastrectomy. Surg Obes Relat Dis. 2010 Sep-Oct;6(5):485-90.

31. Nassif PA, Valadão JA, Malafaia O, Torres OJ, Garcia RF, Klostemann FC. Technical modification for sleeve gastrectomy. Arq Bras Cir Dig. 2013;26 Suppl 1:74-8.

32. Nassif PAN, Fuchs KH, Heimbucher J, Malafaia O, Czeczko NG, Ribas-Filho JM, Thiede A, Dietz UA. Alterações da motilidade antroduodenal e do $\mathrm{pH}$ gástrico após ressecção gástrica parcial incluindo a área correspondente ao marca-passo do estômago de cães. Rev. Assoc. Med. Bras. [online]. 2003; 49(2):196-202.

33. Nelson LG, Gonzalez R, Haines K, Gallagher SF, Murr MM. Amelioration of gastroesophageal reflux symptoms following Rouxen-Y gastric bypass for clinically significant obesity. Am Surg 2005;71:950-3.

34. Pallati PK, Shaligram A, Shostrom VK, et al. Improvement in gastroesophageal reflux disease symptoms after various bariatric procedures: review of the Bariatric Outcomes Longitudinal Database. Surg Obes Relat Dis 2013; pii: S1550-7289(13)00259-1

35. Petersen WV, Meile T, Küper MA, et al. Functional importance of laparoscopic sleeve gastrectomy for the lower esophageal sphincter in patients with morbid obesity. Obes Surg. 2012;22(3):360-6. PMID: 22065341

36. Prachand V, Alverdy JC. Gastroesophageal reflux disease and severe obesity: fundoplication or bariatric surgery? World J Gastroenterol. 2010;16(30):3757-61

37. Prachand VN, Ward M, Alverdy JC. Duodenal switch provides superior resolution of metabolic comorbidities independent of weight loss in the super-obese (BMI Z50 kg/m2) compared with gastric bypass. J Gastrointest Surg 2010;14:211-20.

38. Rocha JRM, Cecconello I, Raimondi AM, Felix VN, Sallum RAA, Oliveira MA, Nasi A, Tacconi MRO, Gama-Rodrigues JJ. Esofagite de refluxo e epitélio colunar ectópico no coto esofágico após gastroplastia cervical. Reavaliação fundamentada em 17 anos de seguimento. ABCD Arq Bras Cir Dig. 2002; 15(1):9
39. Rosenthal RJ; International Sleeve Gastrectomy Expert Panel, Diaz AA, Arvidsson D, Baker RS, Basso N, Bellanger D, Boza C, El Mourad H, France M, Gagner M, Galvao-Neto M, Higa KD, Himpens J, Hutchinson CM, Jacobs M, Jorgensen JO, Jossart G, Lakdawala M, Nguyen NT, Nocca D, Prager G, Pomp A, Ramos AC, Rosenthal RJ, Shah S, Vix M, Wittgrove A, Zundel N. International Sleeve Gastrectomy Expert Panel Consensus Statement: best practice guidelines based on experience of $>12,000$ cases. Surg Obes Relat Dis. 2012 Jan-Feb;8(1):8-19.

40. Santonicola A, Angrisani L, Cutolo P, Formisano G, Iovino P. The effect of laparoscopic sleeve gastrectomy with or without hiatal hernia repair on gastroesophageal reflux disease in obese patients. Surg Obes Relat Dis. 2014 Mar-Apr;10(2):250-5.

41. Sise A, Friedenberg FK.Acomprehensive review of gastroesophageal reflux disease and obesity. Obes Rev. 2008;9:194-203.

42. Soricelli E, Iossa A, Casella G, Abbatini F, Calì B, Basso N. Sleeve gastrectomy and crural repair in obese patients with gastroesophageal reflux disease and/or hiatal hernia. Surg Obes Relat Dis. 2013 May-Jun;9(3):356-61.

43. Tai CM, Huang CK, Lee YC, Chang CY, Lee CT, Lin JT. Increase in gastroesophageal reflux disease symptoms and erosive esophagitis 1 year after laparoscopic sleeve gastrectomy among obese adults. Surg Endosc 2013;27:1260-6.

44. Tutuian R. Effects of bariatric surgery on gastroesophageal reflux. Curr Opin Gastroenterol. 2014 Jul;30(4):434-8.

45. Valezi AC, Herbella FA, Junior JM, de Almeida Menezes $M$. Esophageal motility after laparoscopic Roux-en-Y gastric bypass: the manometry should be preoperative examination routine? Obes Surg. 2012 Jul;22(7):1050-4.

46. Varela JE, Hinojosa MW, Nguyen NT. Laparoscopic fundoplication compared with laparoscopic gastric bypass in morbidly obese patients with gastroesophageal reflux disease. Surg Obes Relat Dis. 2009;5(2):139-143

47. Weiner RA, Weiner S, Pomhoff I, et al. Laparoscopic sleeve gastrectomy-influence of sleeve size and resected gastricvolume. Obes Surg 2007;17:1297-305.

48. Yaghoubian A, Tolan A, Stabile BE, et al. Laparoscopic Roux-en-Y gastric bypass and sleeve gastrectomy achieve comparable weight loss at 1 year. Am Surg 2012; 78:1325-1328 